\title{
Prevalence and Characteristics of Shiga Toxin-Producing Escherichia coli in Swiss Raw Milk Cheeses Collected at Producer Level
}

\author{
R. Stephan, ${ }^{11}$ S. Schumacher, ${ }^{*}$ S. Corti, ${ }^{*}$ G. Krause, $†$ J. Danuser, $\ddagger$ and L. Beutin† \\ *Institute for Food Safety and Hygiene, University of Zurich, Winterthurerstrasse 272, 8057 Zurich, Switzerland \\ †National Reference Laboratory for Escherichia coli, Centre for Infectiology and Pathogen Characterization, \\ Federal Institute for Risk Assessment, Berlin, Germany \\ ‡Federal Veterinary Office, Schwarzenburgstrasse 155, 3003 Bern, Switzerland
}

\section{ABSTRACT}

The aim of this study was to describe the prevalence, serotypes, and virulence genes of Shiga toxin-producing Escherichia coli (STEC) isolated from raw milk cheese samples collected at the producer level with the purpose of determining whether raw milk cheeses in Switzerland represent a potential source of STEC pathogenic for humans. Raw milk cheese samples (soft cheese, $\mathrm{n}=$ 52; semihard and hard cheese, $\mathrm{n}=744$; all produced from Swiss cows', goats', and sheep's milk) collected at the producer level throughout Switzerland within the national sampling plan during the period of March 2006 to December 2007 were analyzed. Of the 432 cheese samples obtained in the year 2006 and the 364 samples obtained in the year 2007, 16 (3.7\%) and $23(6.3 \%)$, respectively, were found to be stx positive. By colony dot-blot hybridization, non-O157 STEC strains were isolated from 16 samples. Of the 16 strains, 11 were typed into 7 E. coli O groups (O2, O15, O22, O91, O109, O113, O174), whereas 5 strains were nontypeable (ONT). Among the 16 STEC strains analyzed, stx $x_{1}$ and $s t x_{2}$ variants were detected in 1 and 15 strains, respectively. Out of the 15 strains with genes encoding for the Stx2 group, 4 strains were positive for $s t x_{2}, 6$ strains for $s t x_{2 \mathrm{~d} 2}, 2$ strains for $s t x_{2-0118}, 1$ strain for $s t x_{2-06}, 1$ strain for $s t x_{2 \mathrm{~g}}, 1$ strain for $s t x_{2}$ and $\mathrm{stx}_{2 \mathrm{~d} 2}$, and 1 strain for $s t x_{2}$ and $s t x_{2 \mathrm{~g}}$. Furthermore, 3 STEC strains harbored $\mathrm{E}-h l y \mathrm{~A}$ as a further putative virulence factor. None of the strains tested positive for eae (intimin). Results obtained in this work reinforce the suggestion that semihard raw milk cheese may be a potential vehicle for transmission of pathogenic STEC to humans.

Key words: raw milk cheese, Shiga toxin-producing Escherichia coli, prevalence, characterization

Received January 28, 2008.

Accepted March 3, 2008.

${ }^{1}$ Corresponding author: stephanr@fsafety.uzh.ch

\section{INTRODUCTION}

Shiga toxin-producing Escherichia coli (STEC) are among the most important causes of food-borne diseases (http://www.who.int/mediacentre/factsheets accessed Apr. 25, 2008; Anonymous, 2007). They are responsible for several human gastrointestinal diseases, including watery or bloody diarrhea. In a proportion of individuals, commonly children, these symptoms may be complicated by neurological and renal sequelae, including hemolytic-uremic syndrome (HUS). Most outbreaks and sporadic cases of hemorrhagic colitis (HC) and HUS have been attributed to strains of serotype O157:H7 STEC. However, especially in continental Europe, the importance of non-O157 STEC; e.g., O26:H11/ H-, O91:H21/H-, O103:H2， O111:H-, O113:H21, O121:H19, O128:H2/H-, and O145:H28/H- as causes of HUS, HC, and other gastrointestinal diseases is being increasingly recognized (Blanco et al., 2004). Non-O157 STEC-associated diseases have probably been underreported because historically many laboratories have screened only for serogroup O157.

The common feature and main virulence factor of STEC is the production of Shiga toxin 1 (Stx1), Shiga toxin 2 (Stx2) or its variants, or a combination of these. Pathogenic STEC strains usually contain other virulence factors such as the outer membrane protein intimin, a protein essential for the intimate attachment and the formation of attaching and effacing lesions on gastrointestinal epithelial cells, enterohemorrhagic $E$. coli (EHEC) hemolysin, or both (Paton and Paton, 1998).

The majority of human infections are correlated with the consumption of contaminated food, particularly undercooked ground beef, unpasteurized milk, and rawmilk products. The STEC can gain access to milk by fecal contamination or by direct excretion (mastitis) from the udder into the milk (Stephan and Kühn, 1999). Public health problems associated with consumption of unpasteurized milk and raw-milk products are well documented by recent food-borne infections (CDC, 1995, 2000; Deschenes et al., 1996; Allerberger et al., 
2001; Lahti et al., 2002; Honish et al., 2005; Espié et al., 2006).

Traditionally, Swiss semihard and hard cheese is typically made from raw milk with the natural microflora responsible for enhancing desirable flavor characteristics of the final product. Although hard cheeses are considered to present a lower risk for growth and survival of pathogens than soft cheeses, STEC can survive also in hard-ripened raw milk cheeses. In fact, also viable STEC appeared to decrease with ripening time, it has been reported that $E$. coli $\mathrm{O} 157: \mathrm{H} 7$ strains were able to survive in hard cheeses up to $90 \mathrm{~d}$ of ripening (Reistma and Henning, 1996; Maher et al., 2001; Schlesser et al., 2006). However, for raw milk cheeses only very limited data on STEC prevalence are available. Recently, 3 groups have reported results for ewes' and caprine milk cheeses in Spain and Peru (Rey et al., 2006; Caro and Garcia-Armesto, 2007; Mora et al., 2007) and 2 groups for raw milk cheeses in France (Pradel et al., 2000; Vernozy-Rozand et al., 2005). For Switzerland, a country with an important cheese industry, such data are lacking.

The aim of this study was to assess the STEC prevalence in raw milk cheese samples, which are collected in the national sampling plan during the years 2006 and 2007. The STEC strains were isolated and further characterized.

\section{MATERIALS AND METHODS}

\section{Sample Collection}

In this study 796 raw milk cheese samples (soft cheese $\mathrm{n}=52$; semihard and hard cheese, $\mathrm{n}=744$ ) collected within the risk-based national sampling plan at the producer level throughout Switzerland during the period of March 2006 to December 2007 were analyzed. These cheeses were produced from Swiss cows' $(\mathrm{n}=722)$, goats' $(\mathrm{n}=63)$, and sheep's $(\mathrm{n}=11)$ milk. From each sample, $25 \mathrm{~g}$ were enriched in $225 \mathrm{~mL}$ of brilliant green bile broth (BBL, Cockeysville, MD) at $42^{\circ} \mathrm{C}$ for $24 \mathrm{~h}$.

\section{Detection of STEC}

For the STEC assay, enrichment samples (brilliant green bile broth) were streaked onto sheep blood agar, and after incubation at $42^{\circ} \mathrm{C}$ for $24 \mathrm{~h}$, colonies were washed off with $2 \mathrm{~mL}$ of $0.85 \%$ saline solution. The plates were incubated at $42^{\circ} \mathrm{C}$ to suppress the growth of Proteus spp., which is a problem when cheese samples are examined. Of each plate eluate, $2 \mu \mathrm{L}$ was then evaluated by PCR with primers based on sequences targeting a region conserved between stx $x_{1}$ and $s t x_{2}$ genes, complementary to nucleotides 447-462 and 943-
962 of sequence EMBL/GenBank M19473 for stx $x_{1}$ and to nucleotide 517-538 and 1016-1035 of sequence EMBL/ GenBank X07865 for stx $x_{2}$ with PCR conditions described previously (Zweifel et al., 2004). For STEC PCR assays, E. coli O157:H7 strain 857/03 (stx $x_{1}$ and stx 2 positive) was used as a positive control.

The PCR assays were performed in a T3 thermocycler (Biometra, Göttingen, Germany). PCR reagents were purchased from Promega (Madison, WI) and primers were synthesized by Microsynth (Balgach, Switzerland). The 50- $\mu \mathrm{L}$ PCR mixtures consisted of $2 \mu \mathrm{L}$ of bacterial suspension boiled at $100^{\circ} \mathrm{C}$ for $10 \mathrm{~min}$ in $42 \mu \mathrm{L}$ of double-distilled water, $5 \mu \mathrm{L}$ of 10 -fold-concentrated polymerase synthesis buffer containing $2.0 \mathrm{mM} \mathrm{MgCl}$, $200 \mu M$ (each) deoxynucleoside triphosphate (dNTP), 30 pmol of each primer, and 2.5 U of Taq DNA polymerase.

\section{Isolation of STEC by Colony Dot-Blot Hybridization}

For the isolation of STEC strains, stx-positive samples were tested by colony hybridization with a DNA probe. The $s t x$ probes were prepared by labeling $s t x$ PCR amplicons from $E$. coli $\mathrm{O} 157: \mathrm{H} 7$ strain 857/03 with DIG High Prime kit (Roche Diagnostics, Mannheim, Germany).

For colony dot-blot hybridization, samples were processed as follows: $100 \mu \mathrm{L}$ of $10^{-5}$ and $10^{-6}$ dilution were plated onto sheep blood agar. After incubation at $42^{\circ} \mathrm{C}$ for $24 \mathrm{~h}$, the dilution with the highest number of individual colonies was selected. Colonies were transferred to a nylon membrane (Roche Diagnostics) by placing the membrane on the surface for $5 \mathrm{~min}$. Membranes were then lysed in denaturation solution $(0.5 \mathrm{~N} \mathrm{NaOH}, 1.5$ $M \mathrm{NaCl})$ for $15 \mathrm{~min}$, placed in neutralization buffer (1.5 $M$ NaCl, $1 M$ Tris-HCl, $\mathrm{pH}$ 7.4) for 15 min and $2 \times \mathrm{SSC}$ (0.3 $M \mathrm{NaCl}, 0.03 M$ sodium citrate) for $10 \mathrm{~min}$. After UV crosslinking for $6 \mathrm{~min}$, baking the dry membranes at $37^{\circ} \mathrm{C}$ for $2 \mathrm{~h}$, colony lift was treated with $1 \mathrm{~mL}$ of proteinase $\mathrm{K}$ solution (Promega) to remove cell debris and washed with $2 \times$ SSC for 15 min. Prehybridization was performed in DIG-Easy-Hyb buffer (Roche) at $42^{\circ} \mathrm{C}$ for about $1 \mathrm{~h}$, and hybridization was carried out at $42^{\circ} \mathrm{C}$ overnight with $5 \mathrm{~mL}$ of hybridization solution containing $100 \mathrm{ng}$ of freshly heat denaturated labeled probes. After washing twice for $15 \mathrm{~min}$ in $2 \times \mathrm{SSC}, 0.1 \%$ SDS at room temperature and then twice for $15 \mathrm{~min}$ in $0.1 \times \mathrm{SSC}, 0.1 \% \mathrm{SDS}$ at $68^{\circ} \mathrm{C}$, the presence of a labeled probe was detected with an alkaline phosphatase-conjugated antibody detection kit and NBT/BCIP stock solution according to the instructions of the manufacturer (Roche). Briefly, hybridized membranes were incubated for 30 min with blocking stock solution (maleic acid buffer with blocking reagent) and for $2 \mathrm{~h}$ with diluted 
Table 1. Characterization results of 16 Shiga toxin-producing Escherichia coli strains isolated from raw milk cheeses at the producer level

\begin{tabular}{|c|c|c|c|c|c|c|c|}
\hline \multirow[b]{2}{*}{ Strain } & \multirow[b]{2}{*}{ Cheese type } & \multirow[b]{2}{*}{ Origin } & \multirow[b]{2}{*}{ Serotype $^{1}$} & \multicolumn{4}{|c|}{ Virulence factor } \\
\hline & & & & $s t x_{1}$ & $s t x_{2}$ & EHEC-hlyA & eae \\
\hline K15_06 & Semihard & Cows' milk & $\mathrm{O} 2: \mathrm{H} 27^{\mathrm{c}}$ & - & $s_{t}{ }_{2}{ }^{\mathrm{a}}$ & - & - \\
\hline K170/3_07 & Semihard & Cows' milk & $\mathrm{O} 2: \mathrm{H} 27^{\mathrm{c}}$ & - & $s t x_{2}^{a}$ & - & - \\
\hline K156_07 & Semihard & Cows' milk & $\mathrm{O} 2: \mathrm{H} 27^{\mathrm{c}}$ & - & $s t x_{2}{ }^{a}$ & - & - \\
\hline K332_06 & Semihard & Goats' milk & $\mathrm{O} 15: \mathrm{H} 16^{\mathrm{b}}$ & - & stx $_{2 \mathrm{~g}}$ & - & - \\
\hline K172/2_07 & Semihard & Cows' milk & $\mathrm{O} 22: \mathrm{H}^{\mathrm{b}}$ & - & $s_{t} x_{2 \mathrm{~d} 2}{ }^{\mathrm{a}}$ & - & - \\
\hline K263_07 & Semihard & Cows' milk & $\mathrm{O} 22: \mathrm{HNM}^{\mathrm{b}}$ & - & $s^{t} x_{2 \mathrm{~d} 2}{ }^{\mathrm{a}}$ & - & - \\
\hline K307/4_06 & Semihard & Cows' milk & O91:H21 ${ }^{b}$ & - & $s_{t} x_{2 \mathrm{~d} 2}{ }^{\mathrm{a}}$ & + & - \\
\hline K331/4_06 & Semihard & Cows' milk & O91:H21 ${ }^{b}$ & - & $s t x_{2 \mathrm{~d} 2}{ }^{\mathrm{a}}$ & + & - \\
\hline K 358_07 & Semihard & Cows' milk & O109:H16 & - & $\begin{array}{l}s t x_{2}{ }^{\mathrm{a}} \\
s t x_{2}\end{array}$ & - & - \\
\hline K133_06 & Semihard & Cows' milk & $\mathrm{O} 113: \mathrm{H} 4^{\mathrm{b}}$ & - & $s x_{2-06}{ }^{\mathrm{a}}$ & - & - \\
\hline K386_06 & Semihard & Cows' milk & $\mathrm{O} 174: \mathrm{H} 21^{\mathrm{b}}$ & - & stx $_{2 \mathrm{~d} 2}{ }^{\mathrm{a}}$ & - & - \\
\hline K138/1_07 & Soft & Goats' milk & ONT:H9 & - & $s t x_{2-0118}$ & - & - \\
\hline K145/2_07 & Soft & Goats' milk & ONT:H9 & - & $s t x_{2-0118}$ & - & - \\
\hline K273_06 & Semihard & Cows' milk & Or:H45 & $s t x_{1}$ & - & - & - \\
\hline K51_07 & Semihard & Cows' milk & Or:HNT & - & $\begin{array}{l}s t x_{2}{ }^{\mathrm{a}} \\
s t x_{2 \mathrm{~d} 2}{ }^{\mathrm{a}}\end{array}$ & + & - \\
\hline K25_07 & Soft & Cows' milk & ONT:HNM & - & stx $_{2 \mathrm{~d} 2}{ }^{\mathrm{a}}$ & - & - \\
\hline
\end{tabular}

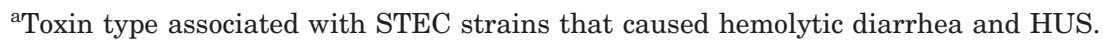

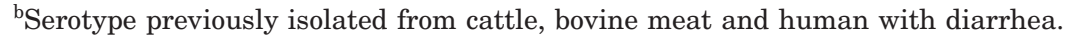

${ }^{\mathrm{c}}$ Serotype previously isolated from cattle and bovine meat.

${ }^{1}$ ONT: O not typeable (O1-181 negative); Or: O rough; NM: nonmotile; HNT: H not typeable.

antibody conjugate solution (blocking stock solution, antibody digoxigenin-AP conjugate, $150 \mathrm{U} / \mathrm{mL}$ ). The unbound antibody conjugate was removed by washing 3 times for 20 min with Dig-wash buffer. Then, membranes were incubated for $1 \mathrm{~h}$ with $10 \mathrm{~mL}$ of freshly prepared color-substrate solution (0.5 $M$ Tris, $\mathrm{pH}$ 9.5, $0.25 M \mathrm{MgCl}_{2}, 0.5 \mathrm{M} \mathrm{NaCl}$, nitro-blue tetrazolium (NBT) $0.5 \mathrm{mg} / \mathrm{mL}, \quad 5$-bromo-4-chloro-3'-indoylphosphate (BCIP) $0.1875 \mathrm{mg} / \mathrm{mL}$ ) in the dark.

One isolate per sample, corresponding to a colored spot, was picked from hybridization plate and grown at $42^{\circ} \mathrm{C}$ overnight on sheep blood agar. Isolated strains were confirmed (i) as $E$. coli by biochemical properties (acid production from mannitol, the o-nitrophenyl- $\beta$-Dgalactopyranoside (ONPG) test, $\mathrm{H}_{2} \mathrm{~S}$ and indole production, and proof of urease and lysine decarboxylase), and (ii) as STEC by detection of stx genes as described above as well as by testing the strains with the ProSpecT Shiga Toxin E. coli Microplate assay (Alexon-Trend, Ramsey, MN).

\section{Serotyping and Genotypic Strain Characterization}

Serotyping of O (lipopolysaccharide) and $\mathrm{H}$ (flagellar) antigens was performed with $\mathrm{O}$-specific and $\mathrm{H}$-specific antisera prepared at the NRL-E. coli (BfR) according to standard methods. Antigens $\mathrm{O} 1$ to $\mathrm{O} 181$ and $\mathrm{H} 1$ to H56 were investigated.

Typing of stx genes was performed by stx-specific PCR and by analysis of RFLP of PCR products (Beutin et al., 2007). The nomenclature proposed by Scheutz and Strockbine (2005) is used for the designation of Shiga toxins. For further genotypic characterization, all isolated strains were examined by PCR for the presence of the eae gene, which encodes intimin, and the EHEC plasmid-encoded hemolysin (E-hly A) gene (Beutin et al., 2004).

\section{RESULTS}

Of the 432 cheese samples obtained in the year 2006 and the 364 samples obtained in the year 2007, 16 (3.7\%; 14 cows' milk semihard cheeses, 1 goats' milk soft cheese, 1 goats' milk semihard cheese) and 23 (6.3\%; 18 cows' milk semihard cheeses, 1 cows' milk soft cheese, 3 goats milk soft cheeses, 1 sheep milk semihard cheese), respectively, were found to be stx positive. By colony dot-blot hybridization, only non-O157 STEC strains were isolated from 16 samples (Table 1). Data obtained after colony hybridization seemed to show that samples contained low numbers of STEC, with high levels of background bacteria.

The strains were confirmed as $E$. coli by their classical biochemical properties. None of the strains produced $\mathrm{H} 2 \mathrm{~S}$ and none was positive for urease, which are very rare features of human STEC. Of the 16 strains 11 were typed into 7 E. coli O groups (O2, O15, O22, O91, O109, O113, O174), whereas 5 strains were nontypeable (ONT). Thirteen strains were typed into 7 different $\mathrm{H}$ types (H4, H8, H9, H16, H21, H27, H45), whereas 3 
were non-typeable. Among the $10 \mathrm{O}: \mathrm{H}$ typeable strains, 7 different serotypes were found: O2:H27, O15:H16, O22:H8, O91:H21, O109:H16, O113:H4, O174:H21. Five of them (O15:H16, O22:H8, O91:H21, O113:H4, O174:H21) are serotypes previously isolated from cattle, bovine meat, and humans with diarrhea. The serotype $\mathrm{O} 2: \mathrm{H} 27$ was previously isolated from cattle and bovine meat.

Among the 16 non-O157 STEC strains analyzed, which all produced Stx in the microplate assay, stx $x_{1}$ and $s t x_{2}$ variants were detected in 1 and 15 strains, respectively. Out of the 15 strains with genes encoding for the Stx2 group, 4 strains were positive for $s t x_{2}, 6$ strains for $s t x_{2 \mathrm{~d} 2}, 2$ strains for $s t x_{2-0118}, 1$ strain for $s t x_{2}$ ${ }_{06}, 1$ strain for $s t x_{2 \mathrm{~g}}, 1$ strain for $s t x_{2}$ and $s t x_{2 \mathrm{~d} 2}$, and 1 strain for $s t x_{2}$ and $s t x_{2 \mathrm{~g}}$. Furthermore, 3 STEC strains harbored E-hlyA as a further putative virulence factor. None of the strains tested positive for eae (intimin).

\section{DISCUSSION}

Until now, only 2 studies from France have reported STEC prevalence data for raw milk cheeses from larger surveys (Pradel et al., 2000; Vernozy-Rozand et al., 2005). Pradel et al. (2000) found that $60(10 \%)$ of 603 cheese samples were positive for stx genes. In their study a STEC strain could be isolated only from $10 \%$ of the PCR-positive cheese samples. In the second study, Vernozy-Rozand et al. (2005) tested 1,039 French raw milk cheeses including soft, hard, unripened, and blue mold cheeses. Thirteen percent (136 of 1,039) were stx positive. They recovered STEC strains from 18 (13\%) of the 136 positive samples. Of the 796 cheese samples collected in our study within the Swiss national sampling plan during this 2 -yr period $39(4.9 \%)$ cheese samples were found to be stx positive. Of the 39 stx PCR positive samples 16 non-O157 STEC strains could be isolated. The $41 \%$ recovery rate in our study was much higher than the commonly described in other studies (Pradel et al., 2000; Fach et al., 2001; Vernozy-Rozand et al., 2005). Moreover, our procedure allows detection of STEC strains independent of their serotype, which is important, because in Switzerland E. coli 0157 is not predominant in cattle and small ruminants (Muehlherr et al., 2003; Al-Saigh et al., 2004; Zweifel et al., 2006). Correspondingly, we obtained different serotypes of STEC of the raw milk cheeses. None of the STEC strains belonged to the classical EHEC types $\mathrm{O} 26: \mathrm{H} 11$, O103:H2, and O157:H7, and none of the isolated STEC strains was positive for the eae gene, which is a virulence trait of classical EHEC.

On the other hand, 11 of the 16 STEC strains from this study were positive for $s t x_{2}, s t x_{2 \mathrm{~d} 2}$, or both. Production of these toxins is an indicator for severe outcome in the infected patients (Bielaszewska et al., 2006). In our study, stx $x_{2}$ and $s t x_{2 \mathrm{~d} 2}$ were found in STEC strains of serotypes O2:H27, O22:H8, O91:H21, O109:H16, and O174:H21. The STEC strains belonging to the serotypes O2:H27, O22:H8, O91:H21, and O174:H21 were already associated with cattle as an animal reservoir (Zweifel et al., 2005) and O22:H8, O91:H21, and O174:H21 were also isolated from patients of all age groups with diarrhea in Germany (Beutin et al., 2004). Strains of the serotypes O91:H21 and 0174:H21 were even identified as agents of HUS in patients from different countries (Bonnet et al., 1998; Pradel et al., 2001). Two strains isolated from a semihard goats' milk cheese and a semihard cows' milk cheese harbored the $s t x_{2 \mathrm{~g}}$ variant, which was recently described as a new, rarely occurring $s t x_{2}$ variant in bovine STEC (Leung et al., 2003). The STEC carrying $s t x_{2 g}$ have not yet been reported to occur in other animals than cattle. Moreover, their role as agents for human disease is not clear. In any case, the finding that a $s t x_{2 g}$ STEC strain is present in cheese makes it likely that humans can be exposed to these STEC types along the food chain.

\section{CONCLUSIONS}

The importance of the STEC group has increased since the first description of a food-borne infection caused by $E$. coli $\mathrm{O} 157: \mathrm{H} 7$. Human STEC infection after raw cheese consumption was first reported by the CDC (1995) and has now gained greater importance, in particular due to the very low minimum infectious dose and the capacity of STEC to survive the raw milk cheese production process. The data presented in this work form part of the risk assessment program for raw milk cheeses in Switzerland and reinforce the suggestion that also semihard raw milk cheese may be a potential vehicle for transmission of pathogenic STEC to humans. Considering the wide distribution of STEC in dairy farms, the carriers represent a source of milk contamination because the fecal carriage of food-borne pathogens among livestock animals is strongly correlated with the hazard of milk contamination. To reduce the risk represented by zoonotic agents to the consumer health, it is essential to reduce contamination of raw milk during the milking processes. Moreover, further studies are needed to evaluate the efficacy of, for example, sub-pasteurization heat treatment of the raw milk in view of inactivation or removal of STEC organisms in milk, which is used for raw milk cheese production.

\section{ACKNOWLEDGMENTS}

The authors wish to thank the cantonal laboratories in the different Swiss cantons for collection of the samples. 


\section{REFERENCES}

Al-Saigh, H., C. Zweifel, J. Blanco, J. E. Blanco, M. Blanco, M. A. Usera, and R. Stephan. 2004. Feacal shedding of Escherichia coli O157, Salmonella spp. and Campylobacter spp. in Swiss cattle at slaughter. J. Food Prot. 4:679-684.

Allerberger, F., M. Wagner, P. Schweiger, H. P. Rammer, A. Resch, M. P. Dierich, A. W. Friedrich, and H. Karch. 2001. Escherichia coli O157 infections and unpasteurized milk. Euro Surveill. $6: 147-151$

Anonymous. 2007. The community summary report on trends and sources of zoonoses, zoonotic agents, antimicrobial resistance and foodborne outbreaks in the European Union in 2006. EFSA J. 130; http://www.efsa.europa.eu/EFSA/efsa_locale-11786207538 12_1178671313012.htm Accessed Apr. 25, 2008.

Beutin, L., G. Krause, S. Zimmermann, S. Kaulfuss, and K. Gleier. 2004. Characterization of Shiga toxin-producing Escherichia coli strains isolated from human patients in Germany over a 3-year period. J. Clin. Microbiol. 42:1099-1108.

Beutin, L., A. Miko, G. Krause, K. Pries, S. Haby, K. Steege, and N. Albrecht. 2007. Identification of human-pathogenic strains of shiga toxin-producing Escherichia coli from food by a combination of serotyping and molecular typing of shiga toxin genes. Appl. Environ. Microbiol. 73:4769-4775.

Bielaszewska, M., A. W. Friedrich, T. Aldick, R. Schurk-Bulgrin, and H. Karch. 2006. Shiga toxin activatable by intestinal mucus in Escherichia coli isolated from humans: Predictor for a severe clinical outcome. Clin. Infect. Dis. 43:1160-1167.

Blanco, J. E., M. Blanco, M. P. Alonso, A. Mora, G. Dahbi, M. A. Coira, and J. Blanco. 2004. Serotypes, virulence genes, and intimin types of Shiga toxin (verotoxin-) producing Escherichia coli isolates from human patients: Prevalence in Lugo, Spain, from 1992 through 1999. J. Clin. Microbiol. 42:311-319.

Bonnet, R., B. Souweine, G. Gauthier, C. Rich, V. Livrelli, J. Sirot, B. Joly, and C. Forestier. 1998. Non-O157 Stx2-producing Escherichia coli strains associated with sporadic cases of haemolyticuremic syndrome in adults. J. Clin. Microbiol. 36:1777-1780.

Caro, I., and M. R. Garcia-Armesto. 2007. Occurrence of Shiga toxinproducing Escherichia coli in a Spanish raw ewe's milk cheese. Int. J. Food Microbiol. 116:410-413.

Centers for Disease Control and Prevention (CDC). 1995. Outbreak of acute gastroenteritis attributable to Escherichia coli serotype O104:H21-Helena, Montana, 1994. MMWR Morb. Mortal. Wkly. Rep. 44:501-503.

Centers for Disease Control and Prevention. 2000. Outbreak of Escherichia coli $\mathrm{O} 157: \mathrm{H} 7$ infection associated with eating fresh cheese curds-Wisconsin, June 1998. MMWR Morb. Mortal. Wkly. Rep. 49:911-913.

Deschenes, G., C. Dasenave, F. Grimont, J. C. Desenclos, S. Benoit, M. Collin, S. Baron, and P. Mariani. 1996. Cluster of cases of haemolytic uraemic syndrome due to unpasteurized cheese. Pediatr. Nephrol. 10:203-205.

Espié, E., V. Vaillant, P. Kariani-Kurkdijian, F. Grimot, R. MartinSchaller, H. De Valk, and C. Vernozy-Rozand. 2006. Escherichia coli $\mathrm{O} 157$ outbreak associated with fresh unpasteurized goats' cheese. Epidemiol. Infect. 134:143-146.

Fach, P., S. Perelel, F. Dilasser, and J. Grout. 2001. Comparison between a PCR-ELISA test and the vero cell assay for detecting Shiga toxin-producing Escherichia coli in dairy products and characterization of virulence traits of the isolated strains. J. Appl. Microbiol. 90:809-818.

Honish, L., G. Predy, N. Hislop, L. Chui, K. Kowalewska-Grochowska, L. Trottier, C. Kreplin, and I. Zazulak. 2005. An outbreak of $E$. coli O157:H7 hemorrhagic colitis associated with unpasteurized gouda cheese. Can. J. Public Health 96:182-184.

Lahti, E., M. Eklund, P. Ruutu, A. Siitonen, L. Tantala, P. Nuorti, and T. Honkanen-Buzalski. 2002. Use of phenotyping and geno- typing to verify transmission of Escherichia coli O157:H7 from dairy farms. Eur. J. Clin. Microbiol. Infect. Dis. 21:189-195.

Leung, P. H., J. S. Peiris, W. W. Ng, R. M. Robins-Browne, K. A. Bettelheim, and W. C. Yam. 2003. A newly discovered verotoxin variant, VT2 $2_{\text {g, }}$ produced by bovine verocytotoxigenic Escherichia coli. Appl. Environ. Microbiol. 69:7549-7553.

Maher, M. M., K. N. Jordan, M. E. Upton, and A. Coffey. 2001. Growth and survival of $E$. coli $\mathrm{O} 157: \mathrm{H} 7$ during the manufacture and ripening of a smear-ripened cheese produced from raw milk. J. Appl. Microbiol. 90:201-207.

Mora, A., S. L. Leon, M. Blanco, J. E. Blanco, C. Lopez, G. Dahbi, A. Echeita, E. A. Gonzales, and J. Blanco. 2007. Phage types, virulence genes and PFGE profiles of Shiga toxin-producing Escherichia coli $\mathrm{O} 157: \mathrm{H} 7$ isolated from raw beef, soft cheese and vegetables in Lima (Peru). Int. J. Food Microbiol. 114:204-210.

Muehlherr, J. E., C. Zweifel, S. Corti, J. E. Blanco, and R. Stephan. 2003. Microbiological quality of bulk-tank raw milk of goat and ewe in Switzerland. J. Dairy Sci. 86:3849-3856.

Paton, J. C., and A. W. Paton. 1998. Pathogenesis and diagnosis of Shiga toxin-producing E. coli infections. Clin. Microbiol. Rev. 11:450-479.

Pradel, N., D. Boukhors, Y. Berin, C. Forestier, C. Martin, and V. Livrelli. 2001. Heterogeneity of Shiga toxin-producing Escherichia coli strains isolated from haemolytic-uremic syndrome patients, cattle, and food samples in central France. Appl. Environ. Microbiol. 67:2460-2468.

Pradel, N., V. Livrelli, Ch. De Champs, J. B. Palcoux, A. Reynaud, F. Scheutz, J. Sirot, B. Joly, and Ch. Forestier. 2000. Prevalence and characterization of Shiga toxin-producing Escherichia coli isolated from cattle, food and children during a one-year prospective study in France. J. Clin. Microbiol. 38:1023-1031.

Reistma, C., and D. R. Henning. 1996. Survival of enterohemorragic Escherichia coli O157:H7 during the manufacture and curing of Cheddar cheese. J. Food Prot. 59:460-464.

Rey, J., S. Sanchez, J. E. Blanco, J. Hermoso de Mendoza, M. Hermoso de Mendoza, A. Garcia, C. Gil, N. Tejero, R. Rubio, and J. M. Alonso. 2006. Prevalence, serotypes and virulence genes of Shiga toxin-producing Escherichia coli isolated from ovine and caprine milk and other dairy products in Spain. Int. J. Food Microbiol. 107:212-217.

Scheutz, F., and N. A. Strockbine. 2005. Escherichia. Pages 607-624 in Bergey's Manual of Systematic Bacteriology. G. M. Garrity, D. J. Brenner, N. R. Krieg, and J. T. Staley, ed. Springer, New York, NY.

Schlesser, J. E., R. Gerdes, S. Ravishankar, K. Madsen, J. Mowbray, and A. Y. Teo. 2006. Survival of a five-strain cocktail of Escherichia coli $0157: \mathrm{H} 7$ during the 60-day aging period of cheddar cheese made from unpasteurized milk. J. Food Prot. 69:990-998.

Stephan, R., and K. Kühn. 1999. Prevalence of verotoxin-producing Escherichia coli (STEC) in bovine $E$. coli mastitis and their antibiotic resistance patterns. J. Vet. Med. B 46:423-427.

Vernozy-Rozand, C., M. P. Montet, M. Berardin, C. Bavai, and L. Beutin. 2005. Isolation and characterization of Shiga toxin-producing Escherichia coli strains from raw milk cheeses in France. Lett. Appl. Microbiol. 41:235-241.

Zweifel, C., M. Kaufmann, J. Blanco, and R. Stephan. 2006. Bedeutung von Escherichia coli O157 beim Schlachtschaf in der Schweiz. Schweiz. Arch. Tierheilk. 148:289-295.

Zweifel, C., S. Schumacher, M. Blanco, J. Blanco, T. Tasara, J. E. Blanco, and R. Stephan. 2005. Phenotypic and genotypic characteristics of non-O157 Shiga toxin producing Escherichia coli from Swiss cattle. Vet. Microbiol. 105:37-45.

Zweifel, C., M. A. Zychowska, and R. Stephan. 2004. Prevalence of Shiga toxin-producing Escherichia coli (STEC), Salmonella spp. and Campylobacter spp. isolated from slaughtered sheep in Switzerland. Int. J. Food Microbiol. 92:45-53. 